\title{
Corrosion Resistance and Adhesion Properties of the Chromium-Free Coating Using an Urethane-Base Resin for AZ91E Magnesium Alloy
}

\author{
Yasumasa Chino $^{1}$, Yoshiaki Mori ${ }^{2}$, Koji Ippongi $^{3}$ and Mamoru Mabuchi ${ }^{1}$ \\ ${ }^{1}$ Institute for Structural and Engineering Materials, National Institute of Advanced Industrial Science and Technology, \\ Nagoya 463-8560, Japan \\ ${ }^{2}$ Aichu Rika Co., Ena 509-7126, Japan \\ ${ }^{3}$ Itochu Polymer Inc., Nagoya 453-0862, Japan
}

Corrosion resistance and adhesion properties of a chromium-free (poison-free) coating using an urethane-base resin for AZ91E Magnesium alloy have been investigated by salt immersion tests and thermal and humid resistance tests. As a result of the salt immersion tests, the corrosion resistance of the chromium-free coated specimen was almost equal to that of the Chromium-based chemical conversion. Also, the thermal and humid resistance tests showed that no changes were found in the coating with an urethane resin base layer; however, exfoliation was observed in the coating with a phenolic resin base layer. In the coating with an urethane resin base layer, the boundaries between the base layer and the aluminum middle layer were relatively flat and there were no pores, though a lot of pores were observed between the base layer and the aluminum middle layer in the coating with a phenolic resin base layer. Therefore, it is suggested that the good adhesion properties of the chromium-free coating are related to the strong adhesion between the urethane resin base layer and the aluminum middle layer.

(Received October 1, 2001; Accepted November 13, 2001)

Keywords: magnesium alloy, surface treatment, chromium free, corrosion resistance property, adhesion property

\section{Introduction}

Magnesium alloys are the lightest alloys used as structural metals and they have some advantages concerning to specific strength, specific elastic modulus and so on. Therefore, large demands, in which they are applied to the structural materials for electric equipments such as cellular phone and television, are expected. ${ }^{1,2)}$ However, some complicated surface treatments are needed to use magnesium alloys for structural metals due to poor corrosion resistance. In the present time, chemical-conversion treatment and chemical and anodic treatment are applied to magnesium alloys as a surface pretreatment. ${ }^{3,4)}$ Powder resin coating fabricated by electrostatic deposition process or fluidized-bed process has widespread use in finish coating for magnesium alloys. ${ }^{5,6}$ ) Recently, chromium-free pretreatments ${ }^{7-10)}$ have been developed for friendly coating in environment. However, some problems such that processes for pretreatment are complicated have not been solved yet. Also, new propositions for effective surface treatment of magnesium alloys such as vapor deposition, ${ }^{11-13)}$ ion implantation ${ }^{14)}$ electroplating, ${ }^{15)}$ polymer plating ${ }^{16)}$ are still in development.

Recently, authors have developed a new coating for magnesium alloys using resin coating, aluminum vapor deposition and finish treatment by resin coating. ${ }^{17}$ Appearance of the coated magnesium alloy prototypes is shown in Fig. 1. One of features of the coating is poison-free coating without chromium. Furthermore, it is possible to change colors of the coating with metallic luster in compliance with various customers' needs with a simple process. Hence, it is expected that the coating is applied to housing of cellular phone, sporting goods such as a golf head and so on.

The present paper describes the corrosion resistance and adhesion properties of the chromium-free coating. The salt immersion tests and thermal and humid resistance tests were

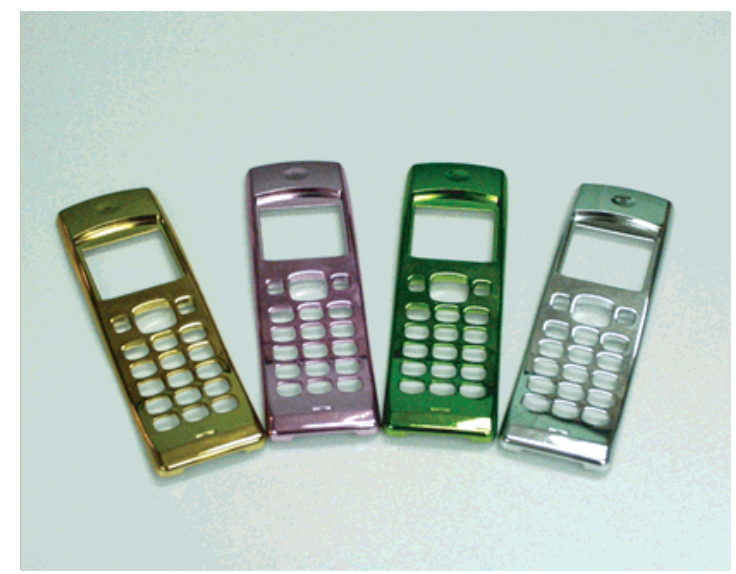

Fig. 1 Appearance of the chromium-free coated magnesium alloy prototypes. ${ }^{17)}$

conducted to investigate the corrosion resistance and adhesion properties. Furthermore, microstructure between the coating layers was investigated. The chromium-free coating is composed of three layers: ${ }^{17)}$ the base layer is an urethane-base resin layer, the middle layer is a vapor deposition layer of pure aluminum, and the top layer is a resin layer. Hence, it is important to investigate boundaries between the coating layers for understanding the high corrosion resistance.

\section{Exrerimental Procedures}

In the present investigation, a magnesium alloy used as bare substrate was AZ91E (Mg-9 mass\%Al-0.8 mass\% $\mathrm{Zn}-$ 0.3 mass $\% \mathrm{Mn}$ ) magnesium alloy fabricated by sand casting. Two kinds of the substrate, whose size were about $12 \times 30 \times$ $5 \mathrm{~mm}^{3}$ and $50 \times 60 \times 5 \mathrm{~mm}^{3}$, were prepared for fabrication of the chromium-free coating. Mechanical polishing by shot peening process and degrease treatment were done for pre- 
treatment of the substrates. An urethane resin was coated on the substrate as a base layer. Then, evaporation and deposition of pure aluminum on the substrate held at room temperature were carried out for about $30 \mathrm{~s}$ under $1 \times 10^{-2} \mathrm{~Pa}$ in vacuum. After the evaporation and deposition of pure aluminum, an acrylic resin was coated on the substrate.

Observation of the cross section of the coating was carried out by an optical microscope (OM) and a field emission scanning electron microscope (FE-SEM).

The corrosion resistance properties of the coated specimens with the size of $12 \times 30 \times 5 \mathrm{~mm}^{3}$ were evaluated by the salt immersion test in which mass loss of the specimens after 24 and $48 \mathrm{~h}$ in 3 mass $\% \mathrm{NaCl}$ solution at $303 \mathrm{~K}$ was measured. In the test, the corrosion resistance of the chromium-free coated specimens was comparably tested with the chromiumbased chemical conversion by MIL-M3171 Type $3^{4,18)}$ and the bare substrate. An acrylic resin was not coated on the chromium-based chemical conversion and the bare substrate.

Adhesion properties of the coating were evaluated by thermal and humid resistance tests with the specimens which had a cross-cut with the length of about $15 \mathrm{~mm}$. In the tests, the coated specimens with the size of $50 \times 60 \times 5 \mathrm{~mm}^{3}$ were exposed to hot air $(358 \mathrm{~K})$, cold air $(233 \mathrm{~K})$, humid air $(98 \%$ and $323 \mathrm{~K}$ ) for $684 \mathrm{ks}$. In addition, adhesion properties of the chromium-free coating were compared with those of another coating whose base-layer was composed of a phenolic-base resin coating. ${ }^{6)}$ The process conditions for the coating with a phenolic resin base layer were the same as those of the coating with an urethane resin base layer.

\section{Results and Discussion}

Cross section of the coating observed by optical microscope (OM) is shown in Fig. 2. The coating was composed of an urethane resin base layer of $10-30 \mu \mathrm{m}$, an aluminum vapor deposition middle layer of less than $5 \mu \mathrm{m}$ and an acrylic-base resin top layer of $10-20 \mu \mathrm{m}$. The total thickness of the coating was $30-60 \mu \mathrm{m}$ (average $50 \mu \mathrm{m}$ ). As a result of the OM observation, defects such as pores were not found and the boundaries between the urethane base layer and the aluminum middle layer were relatively flat.

The salt immersion tests on surface of the specimens were carried out using 3 mass $\% \mathrm{NaCl}$ solution at $303 \mathrm{~K}$. Figure 3 shows the mass loss of the specimens after $24,48 \mathrm{~h}$ in the solution. The mass loss of the bare substrate after $48 \mathrm{~h}$ was $2.3 \times 10^{-3} \mathrm{~kg} / \mathrm{m}^{2}$. On the other hand, that of the chromium-free coated specimen and the chemical conversion after $48 \mathrm{~h}$ was $0.6 \times 10^{-3} \mathrm{~kg} / \mathrm{m}^{2}$ and $0.5 \times 10^{-3} \mathrm{~kg} / \mathrm{m}^{2}$, respectively. Therefore, it is demonstrated that the corrosion resistance of the chromium-free coated specimen is almost equal to that of the chemical conversion, macroscopically.

The thermal and humid resistance tests were carried out for the chromium-free coating. Surface aspects of the coated specimens after the thermal and humid resistance tests are shown in Fig. 4. The coating with an urethane resin base layer did not peel off in the any resistance tests. However, in the coating with a phenolic resin base layer, peeling, which started from the cross-cut, occurred in the any resistance tests. In particular, the coating with a phenolic resin base layer largely peeled off in the case of the high-temperature $(358 \mathrm{~K})$

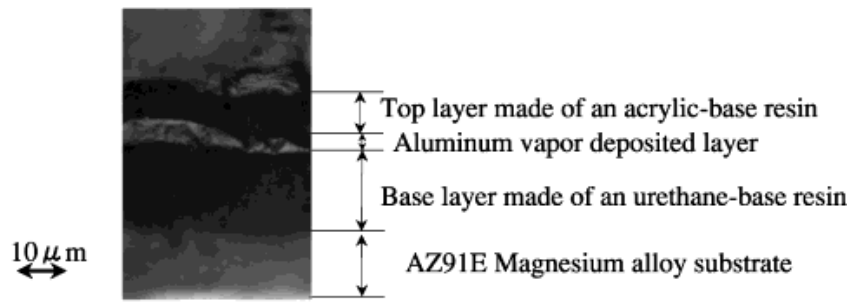

Fig. 2 Cross section of the chromium-free coating for magnesium alloys observed by optical microscope.

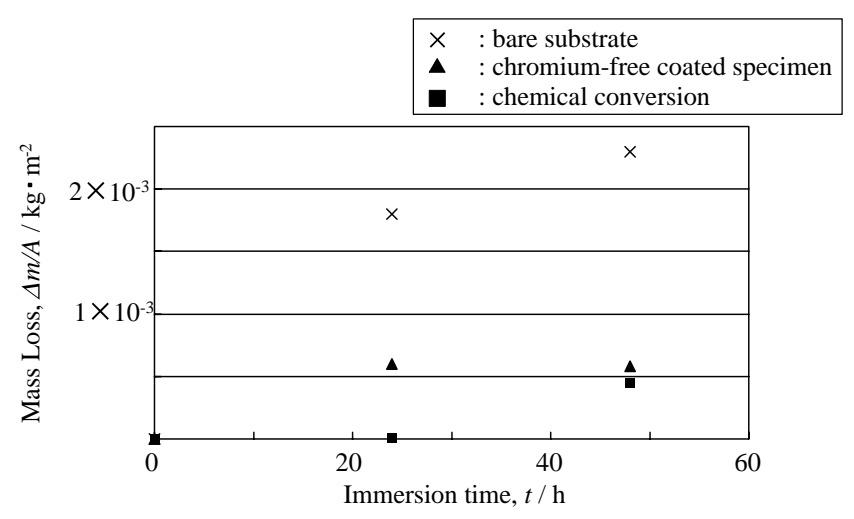

Fig. 3 Variation in mass loss of AZ91E magnesium alloy specimens in 3 mass $\% \mathrm{NaCl}$ solution immersion tests as a function of immersion time.

thermal resistance test and it was difficult to distinguish the cross-cut. The experimental results indicate that the good adhesion properties are attained by applying an urethane resin as the base layer.

Cross section of the coating with a phenolic resin base layer before the thermal and humid resistance tests is shown in Fig. 5. White parts in the photograph show defects of the coating such as pores. A lot of defects were observed in the coating with a phenolic resin base layer. Also, the boundaries between the base layer and the aluminum middle layer were very rough. On the other hand, in the coating with an urethane resin base layer, the boundaries between the base layer and the aluminum middle layer were relatively flat and there were no pores, as shown in Fig. 2. Clearly, microstructure between the base layer and the middle layer is affected by the composition of the base layer. It is likely that the good adhesion properties of the chromium-free coating are related to the strong adhesion between the urethane resin base layer and the aluminum middle layer.

\section{Conclusions}

Corrosion resistance and adhesion properties of the chromium-free coating using an urethane-base resin for AZ91E magnesium alloy have been investigated. The results are summarized as follows:

(1) As a result of the salt immersion tests, the mass loss of the chromium-free coated specimen after $48 \mathrm{~h}$ was almost equal to that of the Chromium-based chemical conversion.

(2) As a result of the thermal and humid resistance tests, adhesion property was improved by selecting an urethanebase resin as a base layer.

(3) The good adhesion properties of the coating is likely 


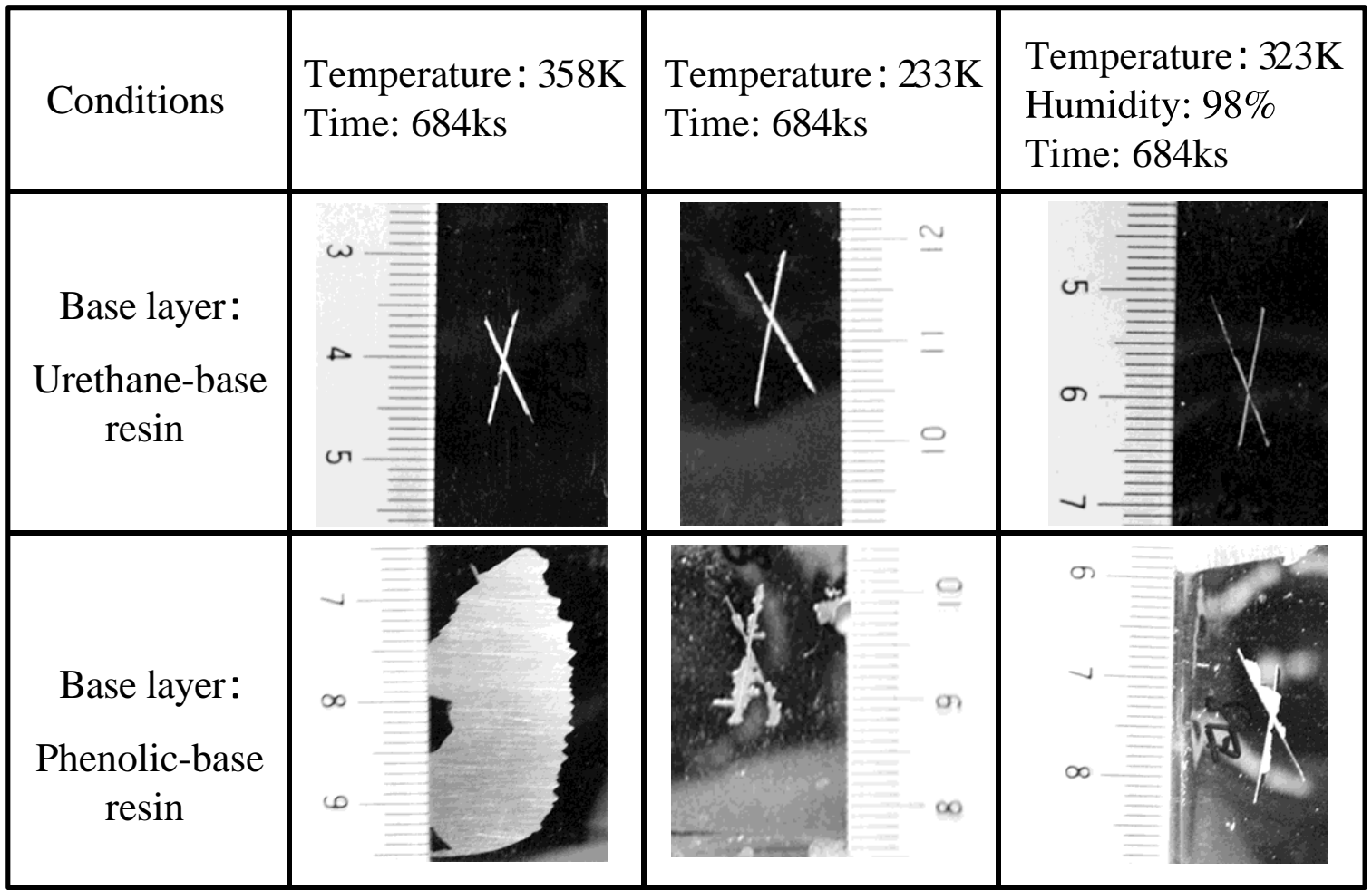

Fig. 4 Results of thermal and humid resistance tests for the chromium-free coating on AZ91E magnesium alloy.

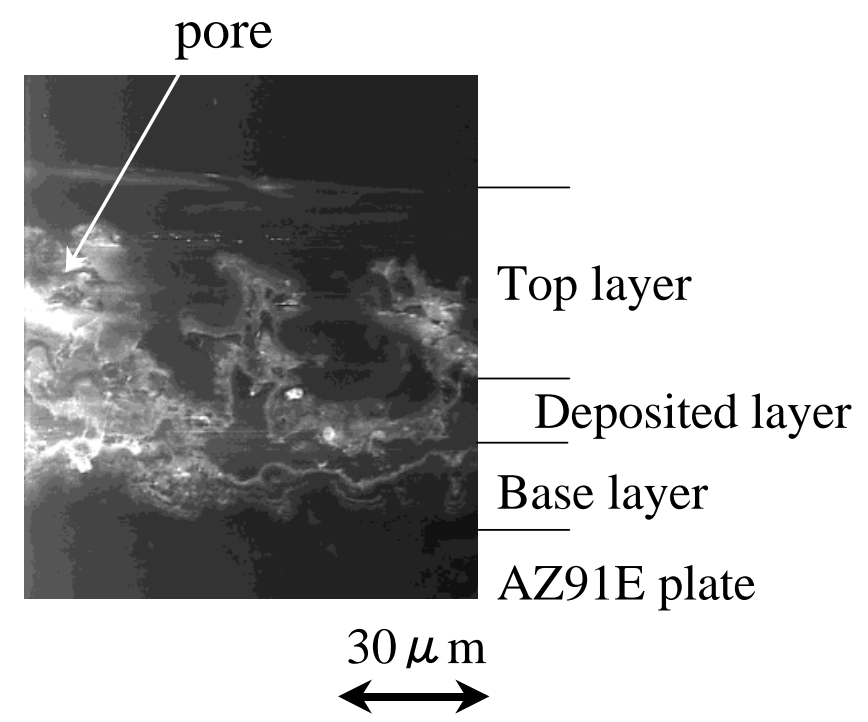

Fig. 5 Cross section of the coating with a phenolic resin base layer before the thermal and humid resistance tests observed by FE-SEM.

to be related to the strong adhesion between the urethane resin base layer and the aluminum middle layer.

\section{Acknowledgments}

The authors are grateful to Mr. S.Yoshida (Tomei Giken Co., LTD) and Mr. T. Kamimura (Kamimura Shinku Co. LTD) for fabrication of the chromium-free coating. M.M. gratefully acknowledges the financial support from the project "Barrier-Free Processing of Materials for Life-Cycle Design for Environment" by Science and Technology Agency of Japan. Also, Y.C. gratefully acknowledges the financial support by Industrial Technology Research Grant Program in 2001 from the New Energy and Industrial Technology Development Organization (NEDO) of Japan.

\section{REFERENCES}

1) B. Landkof: Proc. Magnesium Alloys and Their Applications, ed. by K. U. Kainer (WILEY-VCH Verlag GmbH, Weinheim, 2000) pp. 168-172.

2) S. Hama and F. Watanabe: J. Japan Inst. Light Metals. 51 (2001) 514-515

3) M. Takaya: J. Japan Inst. Light Metal. 50 (2000) 567-576.

4) M. Andesian and Hugh Baker ed.: Magnesium and Magnesium alloys, (ASM internationl, USA, 1999) pp. 143-153.

5) T. Ozaki: HYOMEN GIJUTSU 44 (1993) 925-926.

6) M. Andesian and Hugh Baker ed.: Magnesium and Magnesium alloys, (ASM internationl, USA, 1999) pp. 158-161.

7) J. Skar and D. Albright: Proc. Magnesium Alloys and Their Applications, ed. by K. U. Kainer (WILEY-VCH Verlag GmbH, Weinheim, 2000) pp. 469-474.

8) I. Azkarate, P. Cano, A. Barrio, M. Insausti, P. Coloma: Proc. Magnesium Alloys and Their Applications, ed. by K. U. Kainer (WILEY-VCH Verlag GmbH, Weinheim, 2000) pp. 475-483.

9) M. Takaya: J. Japan Inst. Light Metal. 45 (1995) 713-718.

10) H. Umehara, M. Takaya and Y. Kojima: J. Japan Inst. Light Metal. 50 (2000) 109-115.

11) M. Mino: HYOMEN GIJUTSU 42 (1991) 811-814.

12) Y. Yamamoto, A. Watanabe, K. Sugahara, H. Tsubakino and S. Fukumoto: Scr. Mater. 44 (2001) 1039-1042.

13) Y. Yamamoto, A. Watanabe, K. Sugahara, H. Tsubakino and S. Fukumoto: Mater. Trans. 42(2001) 1237-1242.

14) S. Fukumoto, A. Yamamoto, M. Terasawa, T. Mitamura and H. Tsubakino: Mater. Trans. 42 (2001) 1232-1236.

15) M. Ogata: HYOMEN GIJUTSU 49 (1998) 971-973.

16) K. Mori, H. Hirahara, Y. Oishi and H. Sasaki: Mater. Trans. 42 (2001) 1219-1224.

17) Nikkei Mechanical ed.: Nikkei Mechanical 564 (2001) 87.

18) Japanese Standards Association ed.: JIS H8651 Processes for corrosion protection of magnesium alloys, Japanese Standards Association (1995). 